Portland State University

PDXScholar

\title{
A Comparison of a Group Approach and a Personalized Approach in Teaching Behavior Management Techniques to Parents
}

Vicki Martin

Portland State University

Follow this and additional works at: https://pdxscholar.library.pdx.edu/open_access_etds

Part of the Child Psychology Commons, and the Educational Psychology Commons Let us know how access to this document benefits you.

\section{Recommended Citation}

Martin, Vicki, "A Comparison of a Group Approach and a Personalized Approach in Teaching Behavior Management Techniques to Parents" (1984). Dissertations and Theses. Paper 3334.

https://doi.org/10.15760/etd.3314

This Thesis is brought to you for free and open access. It has been accepted for inclusion in Dissertations and Theses by an authorized administrator of PDXScholar. Please contact us if we can make this document more accessible: pdxscholar@pdx.edu. 
AN ABSTRACT OF THE THESIS OF Vicki Nan Martin for the Master of Science in Psychology presented June 29, 1984.

Title: A Comparison of a Group Approach and a Personalized Approach in Teaching Behavior Management Techniques to Parents.

APPROVED BY MEMBERS OF THE THESIS COMMITTEE:

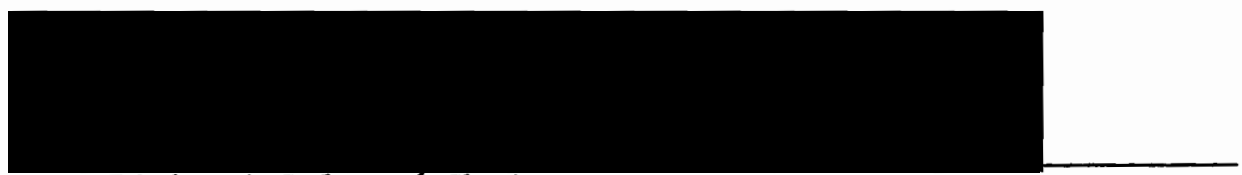

Richard Colman, Chairperson

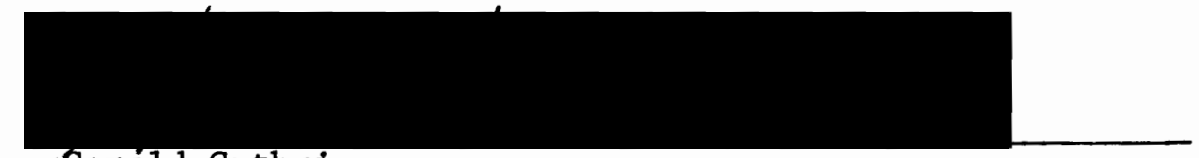

Gerald Guthrie

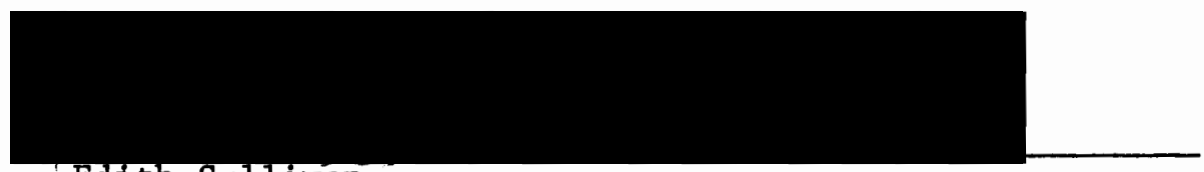

Edith Sullivan

Parent intervention programs that assist parents in increasing their skills in behavior management techniques have experienced considerable success over the last 20 years. Parent training not only aids the parent in changing the child's behavior but may be beneficial in preventing future problems.

When a program of this type is utilized with low income populations, cost effectiveness becomes an important issue. The purpose of the present study was to compare the effectiveness of a parent intervention program when utilizing a group format versus a personalized, one-to-one approach to training. 
The Eyberg Child Behavior Inventory (ECBI) was administered pre and posttreatment to 10 parents of children enrolled in Project Head Start. The experimenter examined the ECBI test results for the subjects in the group condition and personalized condition. Results were mixed with subjects in the group approach decreasing the frequency of their children's problem behaviors while subjects in the personalized condition decreased the number of behaviors that they felt were problems. Although the results indicated that a group approach was more effective in terms of efficiency, further examination of the subjects suggested that the two groups may have consisted of two different populations. 
A COMPARISON OF A GROUP APPROACH AND A PERSONALIZED

APPROACH IN TEACHING BEHAVIOR MANAGEMENT

TECHNIQUES TO PARENTS

by

Vicki Martin

A thesis submitted in partial fulfillment of the requirements for the degree of

MASTER OF SCIENCE

IN

PSYCHOLOGY

Portland State University

1984 


\section{TO THE OFFICE OF GRADUATE STUDIES AND RESEARCH;}

The members of the Committee approve the thesis of Vicki Nan Martin presented June 29, 1984.

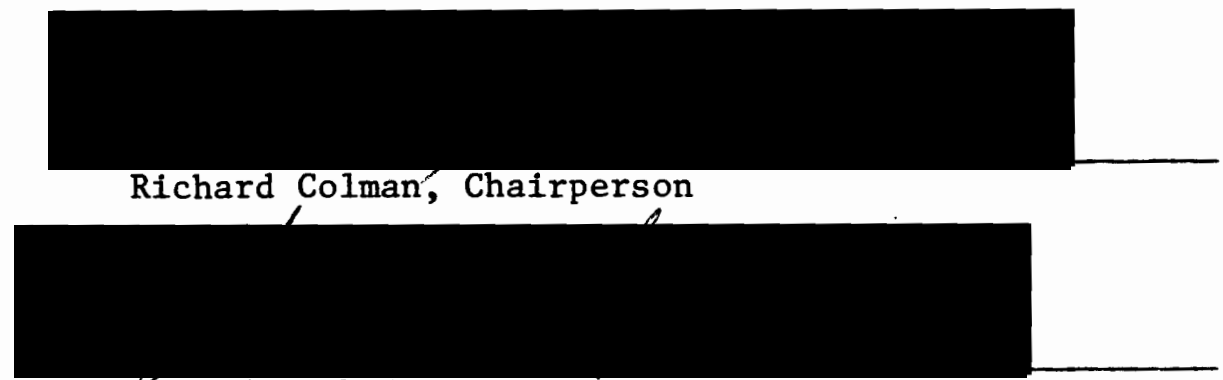

Gerald Guthrie

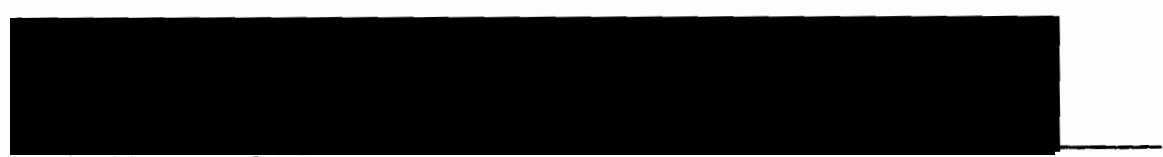

Edith Sullivan

APPROVED :

Roger/Jennings, Head, Department/ of Psychology 


\section{ACKNOWLEDGEMENTS}

I would like to thank the staff at Project Head Start who extended numerous kindnesses to me each time I visited the center, and especially Dr. Richard Colman, without whom this project would not have been feasible. In spite of his crowded schedule, Rich was always patiently available for my numerous questions. Working with him at the Head Start Center was an opportunity that I not only enjoyed but from which I benefited and truly appreciated. As my committee chairperson, he provided invaluable guidance and support.

I would also like to thank my committee members, Dr. Gerald Guthrie and Dr. Edith Sullivan. Edith was consistently concerned and supportive, and Jerry was a source of encouragement and enthusiasm throughout uncountable contacts.

Finally, I would like to thank my parents, who provided the love and support that made this all possible; my friend, Gordon, who patiently instructed me and then kindly let me use his computer; and my children who were patient when I needed it most. 
TABLE OF CONTENTS

PAGE

ACKNOWLEDGEMENTS . . . . . . . . . . . . . . iii

LIST OF TABLES .................... . . . v

LIST OF FIGURES .................... . . . vi

CHAPTER

I INTRODUCTION . . . . . . . . . . . . . 1

II METHOD ...................... 9

III RESULTS .................... 13

IV DISCUSSION . . . . . . . . . . 18

REFERENCES . . . . . . . . . . . . . . . 24

APPENDIX

A EYBERG CHILD BEHAVIOR INVENTORY . . . . . . . 26

B REVISED EYBERG CHILD BEHAVIOR INVENTORY . . . . . 27

C PARENT ATTITUde SCALE . . . . . . . . . . 29

D OUTLINE OF GROUP SESSIONS . . . . . . . . . 30 


\section{LIST OF TABLES}

PAGE

TABLE

I Means, Standard Deviations and Ranges on the ECBI . . • 13

II A Comparison of Mean Intensity Scores and Number of Problems by Age Between Subjects in Both Groups and the Normative Clinic Populations . . . . . . 15

III Pre Test/Post Test Comparison of Means, Standard Deviations, and Ranges in Revised ECBI's Administered Teachers . . . . . . . . . . . . 17 


\section{LIST OF FIGURES}

PAGE

\section{FIGURE}

1. A Comparison of Pre and Post Test Scores of Subjects in the Personalized Condition . . . . . . . . . 16 
CHAPTER I

\section{INTRODUCTION}

Behavior therapy has been successfully used in the traditional clinic setting to aid in the reduction of deviant behaviors of both children and adults. However, research indicates that there are some problems. For example, the artificiality of the clinic setting (the one-hour, one-to-one, weekly meeting) and the possibility that treatment effects may not generalize to the natural environment and be maintained over time are pertinent issues. The new behavior that is developed in the clinic may be extinguished at home and maladaptive behavior reinstated (Patterson, McNeal, Hawkins \& Phelps, 1967; O'Leary \& Wilson, 1975). Lasting change from behavior therapy depends, in part, upon the natural environment of the client maintaining the new behaviors. It would then follow that the clinic provides less environmental control than is needed to make changes persist. It is in the area of child treatment that the natural environment can be controlled by the therapist through family training (Clarke \& Clarke, 1976).

Parents and families can benefit from training in direct coping skills to aid them in dealing with the daily realities of living in a family situation. As mentioned, in traditional therapy, problems don't always appear during the allotted time. In addition, since the relevant environmental details are not known, the therapist 
rarely makes useful, practical suggestions that can be easily translated by the parent into specific behavior (Hawkins, Peterson, Schweid, \& Bijou, 1966).

Sharing skills with parents might also help prevent future problems, hence bringing this approach closer to a prevention model of mental health service, i.e., parents becoming not simply the recipients of therapy but active co-therapists. A study done by Franks and Susskind (1968) successfully individualized training with this result. Several studies have suggested that behavior modification methods can be taught to non-professionals as well as professionals (Wetzel, 1966) and that it is possible for the therapist to structure a treatment so the parents can carry out the therapy (Russo, 1964; Mira, 1970).

One of the reasons that behavior modification techniques work so well in this approach is because they depend more upon the treatment manipulation itself than on the relationship between the client and the therapist (Lang, 1966).

Graziano (1971) put forth ethical reasons for the parents assuming the treatment position. The parents, by virtue of their role, have assumed the major moral, ethical and legal responsibility for their children. They are in closest contact with their children and have the most control over their natural environment. In addition, most parents are traditionally willing and capable of carrying out this moral, ethical and legal responsibility. It would follow that the behavioral goals should also be determined by the parents, as 
they are the responsible agents in direct control of their child's environment (Walder, Cohent, \& Daston, 1967).

Studies done in the controlled environment of the institutional setting with a well-trained staff using a variety of behavior techniques have been very successful in altering problem behaviors. However, these newly acquired behaviors are often rapidly extinguished or don't appear once the child is in an environment that offers a different set of contingencies and discriminative stimuli ( 0 'Leary \& Wilson, 1975). Once again it would seem that an efficient way to approach this is through working with the parents. It is possible that the parents provide those contingencies that result in the reinstatement of the undesirable behavior.

A study done by Dubey and Kaufman (1977) addressed the problem of maintaining changes that are initiated in an institutional setting once the child returns to the natural environment. Using a group approach, parents were trained in methods of social reinforcement and positive contingency management. A follow-up study offered significant results in the reduction of problem severity.

Aiding the parents, whether individually or in groups, in developing behavior management skills that can reduce problem behaviors and maintain desirable behaviors can be successful. Increasing appropriate praise, withdrawal of positive rewards and the encouragement of substitute behaviors which directly compete with the undesirable behaviors are examples of such techniques that work and can be taught. 
Children who are mentally retarded, handicapped, or have serious behavior problems may evoke many negative feelings from their parents, including feelings of helplessness, rage and even hate. Parent intervention has been shown to influence the attitudes and behavior of the mother not only toward the child but in relation to herself as a competent person, capable of improving her situation (Karnes, Teska, Hodgins, \& Badger, 1970). This feeling of more control over her life increases self-esteem which in turn helps eliminate the negative feelings of helplessness, rage and hate toward the child. Since reinforcing desirable behaviors is one of the basic behavior management skills taught parents, it is often necessary to help them recognize these behaviors. Once the parent changes the focus from the child's negative behavior to the positive behavior, a decrease in the negative feelings may be experienced. As parents increase their knowledge of behavior management principles, they also experience a significant increase in self-confidence and these feelings are maintained over time (Rotter, 1975).

One rationale for parent intervention is the belief that permanent changes in parenting styles can occur as the result of parent education with permanent changes in the child's behavior as a consequence. This idea has been supported in follow-up studies that offered significant results in the reduction of undesirable behavior as well as an increase in parental confidence that was maintained over time (Dubey \& Kaufman, 1977).

There are many studies in the literature which support using the clinic setting for parent intervention (Russo, 1964; Humphreys, 
Forehand, McMahon, \& Roberts, 1978). If a behavior approach is used, emphasis initially is on training the parents to identify those factors which are currently maintaining the undesirable behaviors and then teaching them how to alter the reinforcements that they dispense so as to modify the problem behaviors. There are also studies using the behavior modification approach that have utilized the client's natural environment, as well as a combination of the clinic setting and the home. In addition to the parent training in a one-to-one relationship, behavior techniques have also been successfully taught in groups. The research usually consists of group outcome studies that compare the effectiveness of various techniques used in behavior theory or involve a comparison of the effectiveness of using a group format with an individualized approach to training. One such study looked at the advantages of group programming in terms of increased activity and socialization of clients. Twenty hours of training were given to a group of four and 20 hours of training were divided between four clients individually, giving them a total of 5 hours training apiece. The group programs were as effective as individual treatment when staff time was held constant (Storm \& Willis, 1978).

Individualized parent intervention using a behavior theory approach in the natural environment (home) of the client would seem to be the ideal situation since it enables the therapist to have first hand information in assessing the various psychological and environmental factors that currently maintain the undesirable behaviors. From this a decision as to which techniques might best 
be utilized to bring about the desirable results can be made. Further, the home setting offers extended information about the resources avallable to the parent. Research indicates that this type of individualized parent training technique has been successful in eliminating maladaptive behaviors (Hawkins, et al., 1966).

However, is it an efficient approach to parent intervention? While evidence indicates that the family is the most effective and economical system for fostering and maintaining behavior change in the child, one important issue is the economics of the training process. This is of special concern when providing services to low income populations. It seems desirable to combine the most effective methods in the most economical way to serve the greatest number of people. Research literature is limited in this area.

Group training may be as effective yet less costly than individual training. In order to maintain behaviors over time in the natural environment, parents need to have a broad range of problemsolving abilities. Better results are seen when parents are taught general principles of behavior management rather than specific solutions to specific problems (Dubey \& Kaufman, 1977; O'Leary \& Wilson, 1975). A group format seems to foster a presentation of such generalizable information. Materials and procedures can be demonstrated and techniques can be taught through role playing and modeling. The group may also create a situation where the confidence and motivation of parents are reinforced through mutual support and a sense of purpose. The group format, while not eliminating the potential for individualized problem solving, makes it easier to 
focus on techniques and principles useful to every member. In a group, especially a group where the members share similar problems, a person may find that not only can other people be sympathetic but many of them share the same fears and emotions. When problems are shared with others involved in similar situations, a sense of isolation or uniqueness may be reduced through social comparisons (Levy, 1977).

A study performed by Rotter (1975) suggests that information can be taught most efficiently in a group because "social learning theories are the same for every child, regardless of disability." She found that feelings experienced by parents toward their children can be efficiently dealt with using a group format and that feelings of resentment toward the spouse or a professional, which are common occurrences, may also be addressed effectively. Sometimes parents need to get a clear idea of just what is normal and abnormal behavior. Parents' expectations of children's abilities may need to be altered in order to obtain significant effects. A group format can provide such normative and instrumental information.

A criticism of the group format is that the therapist is dependent upon parent report for the identification of the problem behavior and the outcome of intervention. While it is recognized that the parent is subject to a "halo effect" when reporting on a child's behavior, Brofenbrenner (1977) suggests that, although there are potential biases in parent report data, an intervention which fails to produce behavior changes perceptible to the parent is of questionable validity. In addition, Mischel (1968) has shown that a client's 
prediction or self report of his behavior is often more accurate than a clinician's judgment. Teaching clients to observe their own behavior is an important method in behavior analysis and it is likely that this skill is equally effective when training parents to observe the behavior of their child.

Purpose of the Study

The present study attempted to provide parents with skills to produce behavior change in their children. The major purpose of the study was to illustrate that a group approach to training behavior management skills would be as effective as personalized at-home training while requiring less trainer time on a per-subject basis. Two conditions were used. A group condition emphasized general principles of behavior management and addressed the individual problems of its members. The personalized condition utilized the personal knowledge of the resources available to the parent in the home setting. This first-hand information was an aid in developing individually tailored behavior management programs. General principles were also addressed. It was hypothesized that the two conditions would be equally effective in producing behavior change in the child. Measurements of change in child behavior, as indicated on a standardized behavior checklist, would show no difference between the two conditions. 
CHAPTER II

METHOD

\section{Subjects}

Subjects in this study were the parents of children currently enrolled in Project Head Start, a pre-school program for children of low income families. They were selected from a list of parents who either requested assistance with the management of their child's behavior and/or were recommended by Head Start teachers as parents who might be receptive to an intervention program because of their children's behavior problems. The subject population consisted of 12 parents, six in each condition. Subjects who were able to transport themselves to the Head Start center were assigned to the group condition. Subjects without transportation were assigned to the personalized condition. of the subjects in the personalized condition, $80 \%$ were married and $20 \%$ were single parents. The group condition was comprised of $50 \%$ married and $50 \%$ single parents.

The subjects' children ranged in ages from 3.5 to 5.0 years. The mean age of children in the personalized condition was 4.44 years and, for the children in the group condition, 4.46 years.

Two subjects dropped from the group condition following the first session. One subject gave no explanation. The second subject felt that her problems were too great when compared with other group members. Another subject stopped attending the program when she 
began babysitting in her home on a daily basis. Twice, parent or child illness was a factor in absenteeism.

\section{Materials}

The assessment tool used in this study was the Eyberg Child Behavior Inventory (Robinson, Eyberg, \& Ross, 1980), a copy of which is found in Appendix A. This inventory assesses behavior on two dimensions, the frequency of its occurrence and its identification as a problem. It consists of 36 specific behavioral items which the subject answers as to the frequency with which the child engages in these behaviors and whether the behavior is currently a problem. Frequency ratings are done on a 7 point Likert Scale ranging from never to always. This yields an overall behavior intensity score, when summed, with a range of points from 36 to 252 . The Problem scale asks, "Is this behavior a problem for you?" The subject circles "yes" or "no." The number of problems circled are summed (between 1 and 36) to calculate the total problem score. A revised addition of the ECBI (see Appendix B) was also given to each child's teacher prior to the first session and following the final session. The revision was tailored to address behaviors that might occur in the classroom. The teacher was not informed as to which treatment group the child's parent belonged. The subjects in the group treatment condition were to be reissued the ECBI to measure their progress when they had had 4 hours of intervention. This was to be compared with the progress of the subjects in the individual condition at the treatment conclusion. However, this was not done as attendance was 
felt to have been too erratic to have derived valid comparisons. The ECBI was reissued posttreatment to parents in both conditions. In addition, the subjects were also given a parent attitude checklist (see Appendix C) pre and posttreatment. This scale attempted to measure change in attitude toward parenting.

\section{Procedure}

It was initially planned that subjects in the group condition would attend weekly 2-hour meetings for 6 weeks held in a Head Start classroom. Of those parents contacted by telephone, 13 stated that they wanted to participate in the group sessions. They were contacted a second time 1 week prior to the first session and reminded of the date and time. None attended. All 13 were again telephoned 1 day prior to the second session. Six parents attended. From this point on, telephone contact was made 1 day prior to the sessions to remind the subjects that it was scheduled for the following day. For one session this was not done and again no subjects attended. Two additional sessions were added at the end of the initial 6 weeks to compensate for lack of attendance.

The first hour of each session addressed general principles of behavior theory. The second hour involved the application of various behavior management techniques to examples of specific problems. Role modeling was used to demonstrate techniques. Discussion and participation of group members were encouraged. (See Appendix D for an outline of group sessions.) In the personalized parent intervention condition, the trainer made weekly 40 minute visits to each subject's home over a period of 6 weeks. The 
subjects were trained in observation techniques and record keeping. They were taught specific skills in behavior management. An analysis was done of the natural environment in which to implement specific behaviors. General principles of behavior theory were addressed. The ECBI and the parent attitude scale were issued at the beginning of the first session and again at the end of the final session for both conditions.

Teachers were administered the revised ECBI on the day of the first group session and again on the day of the final session. The subjects in the group condition received a total of 12 hours of intervention, or 2 hours of intervention per person. The subjects in the individualized condition received a total of 4 hours of intervention per person. 
CHAPTER III

\section{RESULTS}

The results of a statistical analysis of the pre and post test data collected on the two conditions did not support the hypothesis that the personalized at-home approach to parent training and the group approach to parent training would be equally effective. The Problem scores on the ECBI identified which specific behaviors were problems. The Intensity scores measured the frequency with which those problems occurred.

Central Tendencies and Discriminate Analyses

The pre and post test means, standard deviations, ranges and t-test scores for the Intensity and Problem scores of the two conditions are presented in Table $I$.

TABLE I

MEANS, STANDARD DEVIATIONS AND RANGES ON THE ECBI Intensity Scale

\begin{tabular}{lcccccccc}
\hline & \multicolumn{3}{c}{ Pre Test } & & \multicolumn{2}{c}{ Post Test } & $t-$ Test \\
\hline & $\bar{X}$ & SD & Range & $\bar{x}$ & SD & Range & $\underline{t}$ \\
Personalized & 156.0 & 36.802 & 90 & 143.67 & 29.68 & 72 & $2.23 *$ \\
Group & 107.5 & 22.89 & 47 & 100.25 & 25.9 & 50 & $3.836 *$
\end{tabular}

\footnotetext{
$\begin{aligned}{ }_{*} \mathrm{p} & >.05 \\ * *_{\mathrm{p}} & <.05\end{aligned}$
} 
TABLE I - Continued

Problem Scale

\begin{tabular}{|c|c|c|c|c|c|c|c|}
\hline & Pre & Test & & & Post & Test & $t$-Test \\
\hline & $\overline{\mathrm{x}}$ & $\mathrm{SD}$ & Range & $\overline{\mathrm{X}}$ & $S D$ & Range & $\underline{t}$ \\
\hline Personalized & 21.3 & 9.73 & 24 & 13.167 & 12.59 & 33 & $5.083^{*}$ \\
\hline Group & 7.0 & 2.94 & 8 & 5 & 4.32 & 11 & $1.85 * *$ \\
\hline $\begin{aligned} *_{p} & <.01 \\
* *_{p} & >.05\end{aligned}$ & & & & & & & \\
\hline \multicolumn{8}{|c|}{ Parent Attitude Scale } \\
\hline & Pre & Test & & & Post & Test & $t$-Test \\
\hline & $\overline{\mathrm{x}}$ & SD & Range & $\overline{\mathrm{x}}$ & SD & Range & $\underline{t}$ \\
\hline Personalized & 30.83 & 3.43 & 10 & 32.167 & 4.58 & 10 & $.63^{*}$ \\
\hline Group & 32.5 & 6.245 & 516 & 32.25 & 2.22 & 6 & $1.20 *$ \\
\hline
\end{tabular}

Table II summarizes the comparisons of the pre and post test means of the two subject populations with Eyberg's (1980) normative clinic population. Although there is considerable difference in population size, note the similarity in scores between the group and normative population, and their disparity with the mean scores of the personalized condition.

T tests were performed on each group to evaluate the differences of the means in the ECBI pre and post test scores. The results did not uphold the hypothesis of equal outcome between groups. Subjects in the group training condition demonstrated a significant decrease in problem intensity, $\underline{\mathrm{t}}(3)=3.836, \mathrm{p}<.05$, but no significant difference was found between the pre and post test scores on the 
TABLE II

A COMPARISON OF MEAN INTENSITY SCORES AND NUMBER OF PROBLEMS BY AGE BETWEEN SUBJECTS IN BOTH GROUPS

AND THE NORMATIVE CLINIC POPULATIONS

Pre Test Comparison

\section{Intensity Scale}

Problem Scale

Mean

Age

$\bar{X}$

SD

$\bar{X}$

SD

Clinic

4.5

104.7

32.25

6.65

6.9

Group

4.46

107.5

22.89

7.0

2.94

Personalized

4.44

156.0

36.8

21.3

9.73

Post Test Comparison

\begin{tabular}{|c|c|c|c|c|c|}
\hline & \multicolumn{3}{|c|}{ Intensity Scale } & \multicolumn{2}{|c|}{ Problem Scale } \\
\hline C1inic & 4.5 & 104.7 & 32.25 & 6.65 & 6.9 \\
\hline Group & 4.46 & 100.25 & 25.9 & 5.0 & 4.32 \\
\hline Personalized & 4.44 & 143.67 & 29.68 & 13.17 & 12.59 \\
\hline
\end{tabular}

Problem Scale $(\underline{t}(3)=1.85, \underline{p}>.05)$. Results of a comparison of pre and post test scores in the personalized training condition indicated that there was no significant difference in the intensity of behavior problems, $\underline{t}(5)=2.23, \underline{p}>.05$. Figure 1 illustrates a comparison of the pre and post test Intensity scores for subjects in the personalized condition. However, the results on the Problem Scale demonstrated a significant decrease in behavior problems, $t(5)=5.083, \mathrm{p}<.01$

An analysis of pre and post test data for the parent attitude scale by $\underline{t}$ tests demonstrated no significant pre/post test differences in either the group or the personalized condition. T-test results 


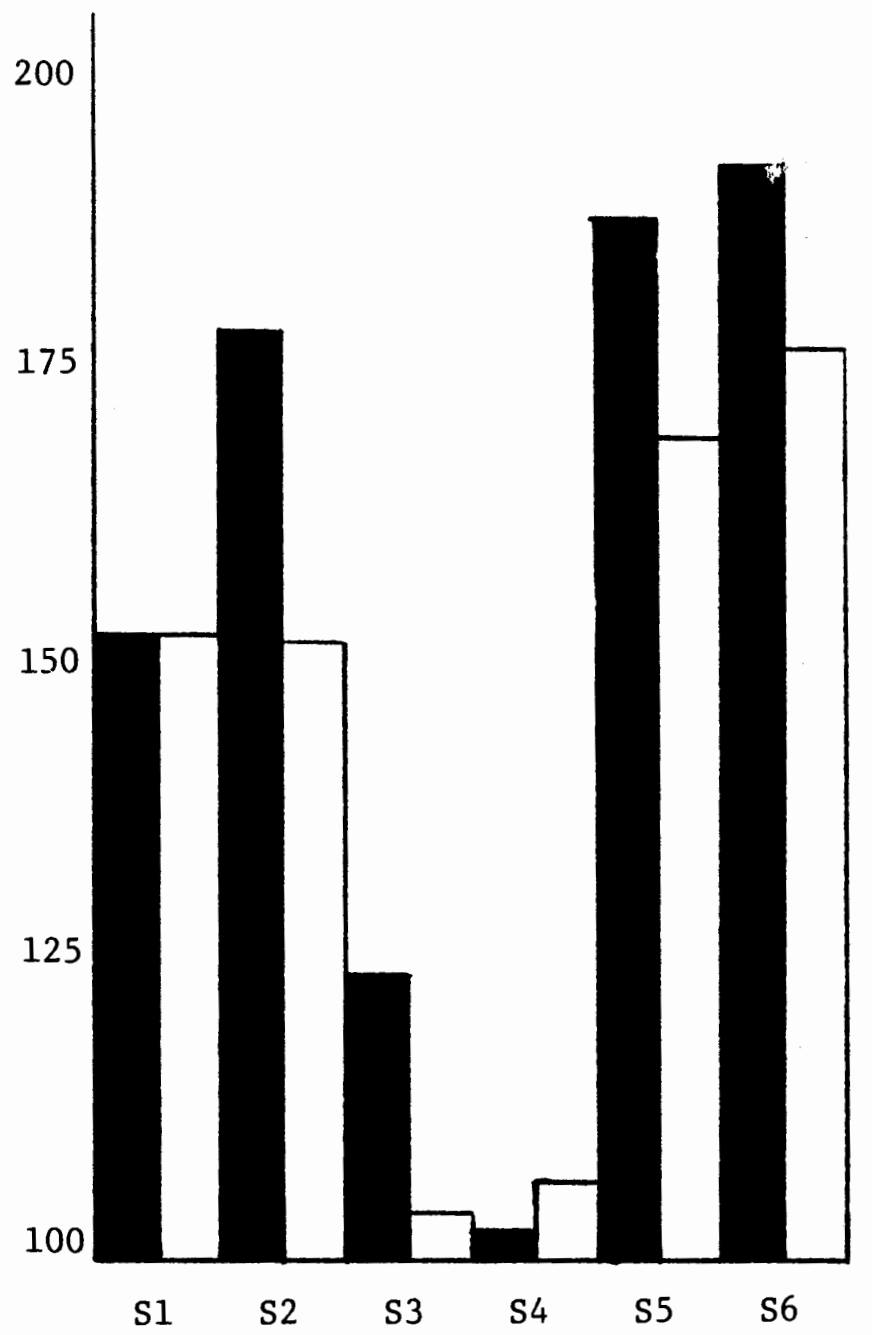

Pre Test Intensity Score

Post Test Intensity Score $\square$

Figure 1. A comparison of pre and post test scores of subjects in the personalized condition. 
for the group condition were $\underline{t}(3)=1.20, \mathrm{P}>.05$, and $\underline{t}(5)=.63$, P > .05 for the personalized condition.

Table III compares the pre and post test means, standard deviations, and ranges for the revised ECBI's administered to the Head Start teachers.

TABLE III

PRE TEST/POST TEST COMPARISON OF MEANS, STANDARD DEVIATIONS, AND RANGES IN REVISED ECBI'S ADMINISTERED TEACHERS

\section{Intensity Scale}

\begin{tabular}{|c|c|c|c|c|c|}
\hline \multicolumn{3}{|c|}{ Pre Test } & \multicolumn{3}{|c|}{ Post Test } \\
\hline $\mathrm{X}$ & SD & Range & $\mathrm{x}$ & SD & Range \\
\hline 78.38 & 30.68 & 89 & 64.63 & 77.84 & 86 \\
\hline \multicolumn{6}{|c|}{ Problem Scale } \\
\hline & re Test & & & st Te & \\
\hline $\mathrm{x}$ & $S D$ & Range & $\mathrm{X}$ & SD & Range \\
\hline 5.13 & 6.62 & 16 & 3.13 & 4.8 & 15 \\
\hline
\end{tabular}

I tests were used to analyze the differences of the means between pre and post test scores on the revised ECBI's administered to the teachers. The results indicated a significant decrease in both the number of behavior problems $(\underline{t}(7)=2.976, \mathrm{p}<.05)$ and the intensity of behavior problems $(\underline{t}(7)=4.64, \mathrm{P}<.01)$. 
CHAPTER IV

\section{DISCUSSION}

The purpose of this study was to investigate the effectiveness of a group approach and a personalized, at-home approach to parent training when working with low income familles. This was a preliminary study and, as such, the results are suggestive and exploratory. However, they provide useful information for the Head Start program and may aid other low income programs as well.

The data relied on parent and teacher observation. No mandatory record-keeping or homework was required as previous experience with this population suggested that these types of contingencies would decrease rather than increase the subjects' motivation. Our impression was that the demand on this population would increase attendance problems.

The group condition had significant results in the reduction of behavior problem intensity and yet received only half of the training time on a per subject basis. Given this information it could be interpreted that this approach was more effective than the personalized, at-home approach to parent training. First, however, there are several considerations.

On a per subject basis, each subject received 2 hours of training, while the subjects in the personalized condition received a total of 4 hours of training. Yet no subject in the group condition 
attended more than four of the six sessions, and for two sessions there were only two subjects present. The assumption of only 2 hours of intervention per subject is based on the four subjects attending the same four sessions.

The sample size was small. This and the fact that there was no control group suggests using caution when internreting the results.

It is interesting to note that, while the scores on the Intensity Scale decreased in the group condition, those on the Problem Scale did not. Perhaps the group support and information supplied by this kind of a format was helpful to the participants in that they may not have felt their problems were as bad once they knew that others had problems, too.

There are practical implications to consider in both the group and personalized conditions, and the time and energy expended by the trainer is of central importance. How to motivate group members to attend the sessions is a major problem. Research findings indicate that programs using contingencies have had significantly greater parental cooperation than groups attended on a strictly voluntary basis (Mira, 1970; Eyberg \& Johnson, 1974). The telephone calls used as a reminder to subjects in this study were not part of the initial program design. Approximately 20 minutes per week were spent in attempts to contact subjects. Therefore, a total of 2 additional hours of trainer time was required for the group condition. It appeared evident that without the telephone calls attendance would have further decreased or become nonexistent. As it was, two sessions had to be added at the end of the 6 weeks. 
Although there were problems, evidence suggests that parent intervention training using a group format can be successful. However, the group format may only be available to a certain population. Research indicates that intervention can be successful for those low income people at the upper end of the low income range. Families at the most deprived levels of income may be too overburdened with survival tasks and lack the social support necessary to effectively organize themselves to participate in a group situation (Radin, Weikart, 1967). The subjects were assigned to each condition depending on transportation. The availability of transportation as well as those organizational skills necessary to attend a group function may constitute the condition that exemplify two different populations. The mean score on the pre test for the group condition was only slightly higher (see Table II) than that of the normative population for both Intensity and Problem scales. Scores following the treatment were lower than those of the normative population. This is not the case in the personalized condition. Pre and post test scores on both scales were considerably higher than the means of the normative population. It is important to note that the ECBI was normed on a pediatric population with a low percentage $(5.6 \%)$ of subjects who were identified as having conduct problem behaviors (Robinson, et al., 1980). A frequency count demonstrated that subjects in the two conditions were concerned with different types of problems. Those problems cited most frequently at high intensity levels by subjects in the personalized condition involved noncompliant behaviors while those cited by subjects in the group condition did not. These results 
lend support to the idea that the subjects in this study comprised two different populations. Further research is suggested here.

It is evident from these comparisons that subjects in the personalized condition had more problems to begin with. This does not mean that they were not motivated or would not accept or appreciate help. On the contrary, these subjects were always home for their appointments or, if there was a conflict, contacted the Head Start office with this information and rescheduled their time. The prevailing attitude was friendly and appreciative. There was no question that these subjects were willing to work and capable of benefiting from help.

Although the results of their Intensity scores were not significant, the trend was toward a decrease in problem intensity (see Figure 1). It is possible that an increase of intervention time would bring significant results in this area. The question is how much time would be needed. The mean scores on the Problem Scale did decrease significantly and it is difficult to determine why this happened. Perhaps simply having someone to talk to about these behaviors reduced some of the anger and other negative feelings these parents may have had about their child, with an increase in tolerance as the result. There may also have been a reduction in the feelings of helplessness in dealing with their child's problem behaviors. It would be of interest to see if this score would decrease as much simply by having someone to talk to about their problems, as it did with the training. 
The similarity of mean scores between the group population and Eyberg's normative population on the ECBI suggests that those subjects in the group condition might not really be in need. Perhaps their children would improve without intervention. It would be interesting to use a control group with the group training approach for comparison. As the research suggests, it is likely that there is a segment of the low income population whose problems are too great to benefit from a parent training program. It is possible that the subjects in the personalized training condition would have been seen as being part of this group if an at-home intervention program had not been offered. An important question is, "How do we identify who needs help?" Which parents can succeed in the less personal format of the group and which need a more personalized approach? Populations of clients may be defined by scores on reliable measures, such as the Life Events Scale, to help identify those parents who need one-to-one intervention before they can benefit from a group. Perhaps giving the parents the option of a group or personalized training would be adequate. It is possible that they themselves know best where they belong.

The mean Intensity scores and Problem scores on the teachers' revised ECBI's measured significant pre and post test decreases on both scales. However, these teachers knew which of their students' parents were receiving parent training. Although they were not aware as to which condition the parent had been assigned, it is likely they still would have expected to see improvement in the children's behavior. Therefore, any follow-up studies might benefit 
by having a control group of students and not informing the teachers as to which parent is receiving intervention and which is not.

\section{$\underline{\text { Summary }}$}

The present study attempted to demonstrate that subjects in a group situation would increase their parenting skills equally with subjects receiving personalized training. Results indicated that a group format was more successful, both in terms of outcome and efficiency. However, close examination of the subject population suggests, not only that there may be two separate populations within this low income group, but that those subjects in the group condition may not even be in need of intervention. Of course, the sample size was small and the subjects limited to parents of children enrolled in Project Head Start. These parents may differ in some way from parents encountered in another low income program or in the community at large.

Although, the results of the ECBI were utilized chiefly to measure and compare change between the two groups, this assessment tool may have additional value in helping pinpoint those individuals within the subject population that can best benefit from a parent intervention program. 
REF ERENCES

Berkowitz, B. P., \& Graziano, A. M. (1972). Training parents as behavior therapists: A Review. Behavior Research and Therapy, 10, 297-317.

Boardman, W. K. (1962). Rusty: A brief behavior disorder. Journal of Consulting Psychology, 26, 293-297.

Brofenbrenner, U. (1977). Toward an experimental ecology of human development. American Psychologist, 32, 513-531.

Clarke, A. M., \& Clarke, A. D. B. (1976). Early experience: Myth and evidence. New York: McMillan Publishing, Inc.

Dubey, D. R., \& Kaufman, K. F. (1977, August). Teaching behavior management skills to parents: The group approach. Paper presented at the $85 \mathrm{th}$ Annual Convention of the APA, San Francisco, CA.

Eyberg, S. M., \& Johnson, S. M. (1974). Mu1tiple assessment of behavior modification with families: Effects of contingency contracting and order of treated problems. Journal of Consulting and Clinical Psychology, 42, 594-606.

Franks, C. M., \& Susskind, D. J. (1968). Behavior modification with children: Rationale and technique. Journal of School Psychology, 6, 75-88.

Graziano, A. M. (1971). Behavior therapy with children. New York: Aldine-Atherton.

Hartman, J. J. (1979). Small group methods of personal change. Annual Review of Psychology, 30, 453-476.

Hawkins, R. P., Peterson, R. F., Schweid, E., \& Bijou, S. W. (1966). Behavior therapy in the home: Amelioration of problem parentchild relations with the parent in a therapeutic role. Journal of Experimental Child Psychology, 4, 99-107.

Humphreys, L., Forehand, R., McMahon, R., \& Roberts, M. (1978). Parental behavioral training to modify child noncompliance: Effects on untreated siblings. Journal of Behavior Therapy and Experimental Psychiatry, 9 (3), 235-238. 
Karnes, M. B., Teska, J. A., Hodgins, A. S., \& Badger, E. D. (1970). Educational intervention at home by mothers of disadvantaged infants. Child Development, 41, 925-935.

Lang, P. J. (1966). The transfer of treatment. Journal of Conslilting Psychology, 30(5), 375-378.

Levy, L. H. (1977). Self-help groups: Types and psychological processes. Journal of Applied Behavioral Science, 12, 310-322.

Mira, M. (1970). Results of a behavior modification training program for parents and teachers. Behavior Research and Therapy, $\underline{8}(3)$, 309-311.

Mische1, W. (1968). Personality and Assessment. New York: McGraw Hill.

O'Leary, D. K., \& Wilson, T. G. (1975). Behavior Therapy: Application and Outcome. Englewood Cliffs, N. J.: Prentice-Ha11, Inc.

Patterson, G. R., McNeal, S., Hawkins, N., \& Phelps, R. (1967). Reprogramming the social environment. Journal of Child Psychology and Psychiatry, $\underline{8}, 181-195$.

Radin, N., \& Weikart, D. (1967). A home teaching program for disadvantaged preschool children. Journal of Special Education, 1, $183-190$.

Robinson, E. A., Eyberg, S. M., \& Ross, A. W. (1980). The standardization of an inventory of child conduct problem behaviors. Journal of Clinical Child Psychology, Spring, 22-28.

Rotter, D. (1975). Group parent therapy: Behavior/dynamic approach to parent training. Paper presented at the annual meeting of the American Association on Mental Deficiency, Portland, OR.

Russo, S. (1964). Adaptations in behavior therapy with children. Behavior Research and Therapy, 2, 43-47.

Storm, R. H. \& Willis, J. H. (1978). Small group training as an alternative to individual programs for profoundly retarded persons. American Journal of Mental Deficiency, 83 (3), 283-288.

Walder, L. 0., Cohent, S. I., \& Daston, P. G. (1967). Cited in Berkowitz, B. P., \& Graziano, A. M. (1972). Training parents as behavior therapists: A Review. Behavior Research and Therapy, 10, 297-317.

Wetzel, R.J. (1966). Outpatient treatment of artistic behavior Behavior Research and Therapy, 4, 196-177. 
EYBERG CIIII BPHAVICR INTENTORY

Directions: Belorv are a series of phrases that describe children's behavior. Please (1) circle the number describing how of ten the behavior currently occurs with your child, and (2) circle either "yes" or "no" to indicate whether the behavior is current1y a problem.

1. Dawdles in getting dressed

2. Dawdles or lingers at meal time

3. Has poor table manners

4. Refuses to eat food presented

5. Refuses to do chores when asked

6. Slow in getting ready for bed

7. Refuses to go to bed on time

8. Does not obey house rules on his own

9. Retuses to obey until threatened with punishment

10. Acts defiant when told to do something

11. Argues with parents about rules

12. Gets angry when doesn't get his oun way

13. Has temper tantrums

14. Sasses adults

15. Thines

16. Cries easily

17. Yells or screams

18. Hits parents

19. Destroys toys and other objects

20. Is careless with toys and other objects

21. Steals

22. Lies

23. Teases or provokes other children

24. Verbally fights with friends his own age

25. Verbally fights with sisters and brothers

26. Physically fights with friends his own age

27. Physically fights with sisters and brothers

28. Constantly seeks attention

29. Interrupts

30. Is easily distracted

31. Has short attention span

32. Fails to finish tasks or projects

33. Has difficulty entertaining himself alone

34. Has difficulty concentrating on one thing

35. Is overactive or restless

36. Wets the bed
How of ten does this occur with your child?

Never Seldom Sometimes Often Always

$\begin{array}{lllllll}1 & 2 & 3 & 4 & 5 & 6 & 7\end{array}$

$\begin{array}{lllllll}1 & 2 & 3 & 4 & 5 & 6 & 7\end{array}$

Is This a

Problem for You?

$\begin{array}{lllllll}1 & 2 & 3 & 4 & 5 & 6 & 7\end{array}$

$\begin{array}{lllllll}1 & 2 & 3 & 4 & 5 & 6 & 7\end{array}$

$\begin{array}{lllllll}1 & 2 & 3 & 4 & 5 & 6 & 7\end{array}$

Yes

No

Yes No

Yes No

Yes No

Yes No

Yes No

$\begin{array}{lllllll}1 & 2 & 3 & 4 & 5 & 6 & 7\end{array}$

Yes

No

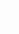

$\begin{array}{lllllllll}1 & 2 & 3 & 4 & 5 & 6 & 7 & \text { Yes } & \text { No }\end{array}$

$\begin{array}{lllllllll}1 & 2 & 3 & 4 & 5 & 6 & 7 & \text { Yes } & \text { No }\end{array}$

$\begin{array}{lllllllll}1 & 2 & 3 & 4 & 5 & 6 & 7 & \text { Yes } & \text { No }\end{array}$

$\begin{array}{lllllllll}1 & 2 & 3 & 4 & 5 & 6 & 7 & \text { Yes }\end{array}$

$\begin{array}{lllllllll}1 & 2 & 3 & 4 & 5 & 6 & 7 & \text { Yes } & \text { No }\end{array}$

$\begin{array}{llllllllll}1 & 2 & 3 & 4 & 5 & 6 & 7 & \text { Yes No }\end{array}$

$\begin{array}{lllllllll}1 & 2 & 3 & 4 & 5 & 6 & 7 & \text { Yes No }\end{array}$

$\begin{array}{lllllllll}1 & 2 & 3 & 4 & 5 & 6 & 7 & \text { Yes } & \text { No }\end{array}$

$\begin{array}{lllllllll}1 & 2 & 3 & 4 & 5 & 6 & 7 & \text { Yes No }\end{array}$

$\begin{array}{lllllllll}1 & 2 & 3 & 4 & 5 & 6 & 7 & \text { Yes } & \text { No }\end{array}$

$\begin{array}{lllllllll}1 & 2 & 3 & 4 & 5 & 6 & 7 & \text { Yes No }\end{array}$

$\begin{array}{lllllllll}1 & 2 & 3 & 4 & 5 & 6 & 7 & \text { Yes No }\end{array}$

$\begin{array}{lllllllll}1 & 2 & 3 & 4 & 5 & 6 & 7 & \text { Yes } & \text { No }\end{array}$

$\begin{array}{lllllllll}1 & 2 & 3 & 4 & 5 & 6 & 7 & \text { Yes No }\end{array}$

$\begin{array}{lllllllll}1 & 2 & 3 & 4 & 5 & 6 & 7 & \text { Yes No }\end{array}$

$\begin{array}{llllllllll}1 & 2 & 3 & 4 & 5 & 6 & 7 & \text { Yes No }\end{array}$

$\begin{array}{lllllllll}1 & 2 & 3 & 4 & 5 & 6 & 7 & \text { YeS } & \text { No }\end{array}$

$\begin{array}{lllllllll}1 & 2 & 3 & 4 & 5 & 6 & 7 & \text { Yes No }\end{array}$

$\begin{array}{lllllllll}1 & 2 & 3 & 4 & 5 & 6 & 7 & \text { Yes } & \text { No }\end{array}$

$\begin{array}{lllllllll}1 & 2 & 3 & 4 & 5 & 6 & 7 & \text { Yes } & \text { No }\end{array}$

$\begin{array}{lllllllll}1 & 2 & 3 & 4 & 5 & 6 & 7 & \text { Yes } & \text { No }\end{array}$

$\begin{array}{lllllllll}1 & 2 & 3 & 4 & 5 & 6 & 7 & \text { Yes }\end{array}$

$\begin{array}{lllllllll}1 & 2 & 3 & 4 & 5 & 6 & 7 & \text { Yes No }\end{array}$

$\begin{array}{lllllllll}1 & 2 & 3 & 4 & 5 & 6 & 7 & \text { Yes No }\end{array}$

$\begin{array}{lllllllll}1 & 2 & 3 & 4 & 5 & 6 & 7 & \text { Yes } & \text { No }\end{array}$

$\begin{array}{lllllllll}1 & 2 & 3 & 4 & 5 & 6 & 7 & \text { Yes No }\end{array}$

$\begin{array}{lllllllll}1 & 2 & 3 & 4 & 5 & 6 & 7 & \text { Yes } & \text { No }\end{array}$

$\begin{array}{lllllllll}1 & 2 & 3 & 4 & 5 & 6 & 7 & \text { Yes No }\end{array}$

$\begin{array}{lllllllll}1 & 2 & 3 & 4 & 5 & 6 & 7 & \text { Yes No }\end{array}$


APPENDIX B

Revised Eyberg Chtld Behavior Inventory

Rater's Name

Relationship to ChIld

Date of Rating

Child's Name

Child's Age

Birthdate

Directions: Below are a series of phrases that describe children's behavior. Please

(1) circle the number describing how often the behavior currently occurs with this child, and (2) circle either "yes" or "no" to indicate whether the behavior is currently a problem.

How often does this

occur with this child?

Never Seldom Sometimes Often Always
Is this a

Problem

for You?

1. Dawdles in putting on/taking off coat

2. Dawdles or lingers at mealtime

3. Has poor table manners

4. Refuses to eat food presented

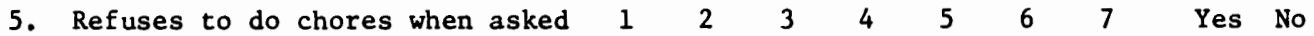

$\begin{array}{lllllllll}1 & 2 & 3 & 4 & 5 & 6 & 7 & \text { Yes No }\end{array}$

$\begin{array}{llllllll}1 & 2 & 3 & 4 & 5 & 6 & 7 & \text { Yes No }\end{array}$

$\begin{array}{lllllllll}1 & 2 & 3 & 4 & 5 & 6 & 7 & \text { Yes } & \text { No }\end{array}$

$\begin{array}{lllllllll}1 & 2 & 3 & 4 & 5 & 6 & 7 & \text { Yes No }\end{array}$

6. Does not obey school rules on his own

$\begin{array}{llllllll}1 & 2 & 3 & 4 & 5 & 6 & 7 & \text { Yes No }\end{array}$

7. Refuses to obey until threatened with punishment

$\begin{array}{llllllll}1 & 2 & 3 & 4 & 5 & 6 & 7 & \text { Yes No }\end{array}$

8. Acts defiant when told to do something

9. Argues with teachers about rules

$\begin{array}{llllllll}1 & 2 & 3 & 4 & 5 & 6 & 7 & \text { Yes No }\end{array}$

10. Gets angry when doesn't get his own way

11. Has temper tantrums

$\begin{array}{llllllll}1 & 2 & 3 & 4 & 5 & 6 & 7 & \text { Yes No }\end{array}$

12. Sasses adults

$\begin{array}{llllllll}1 & 2 & 3 & 4 & 5 & 6 & 7 & \text { Yes No }\end{array}$ 
Never Seldom Sometimes Often Always

13. Whines

14. Cries easily

15. Yells or screams

16. Hits teachers

17. Destroys toys and other objects

18. Is careless with toys and other objects

19. Steals

20. Lies

21. Teases or provokes other children

22. Verbally fights with friends his own age

23. Physically fights with friends his own age

24. Constantly seeks attention

25. Interrupts

26. Is easily distracted

27. Has short attention span

28. Fails to finish tasks or projects

29. Has difficulty entertaining himself alone

30. Has difficulty concentrating on one thing

31. Is overactive or restless $\begin{array}{lllllllll}1 & 2 & 3 & 4 & 5 & 6 & 7 & \text { Yes No }\end{array}$

$\begin{array}{llllllll}1 & 2 & 3 & 4 & 5 & 6 & 7 & \text { Yes No }\end{array}$

$\begin{array}{llllllll}1 & 2 & 3 & 4 & 5 & 6 & 7 & \text { Yes No }\end{array}$

$\begin{array}{llllllll}1 & 2 & 3 & 4 & 5 & 6 & 7 & \text { Yes No }\end{array}$

$\begin{array}{llllllll}1 & 2 & 3 & 4 & 5 & 6 & 7 & \text { Yes No }\end{array}$

$\begin{array}{llllllll}1 & 2 & 3 & 4 & 5 & 6 & 7 & \text { Yes No }\end{array}$

$\begin{array}{llllllll}1 & 2 & 3 & 4 & 5 & 6 & 7 & \text { Yes No }\end{array}$

$\begin{array}{llllllll}1 & 2 & 3 & 4 & 5 & 6 & 7 & \text { Yes No }\end{array}$

$\begin{array}{llllllll}1 & 2 & 3 & 4 & 5 & 6 & 7 & \text { Yes No }\end{array}$

$\begin{array}{llllllll}1 & 2 & 3 & 4 & 5 & 6 & 7 & \text { Yes No }\end{array}$

$\begin{array}{llllllll}1 & 2 & 3 & 4 & 5 & 6 & 7 & \text { Yes No }\end{array}$

$\begin{array}{llllllll}1 & 2 & 3 & 4 & 5 & 6 & 7 & \text { Yes No }\end{array}$

$\begin{array}{llllllll}1 & 2 & 3 & 4 & 5 & 6 & 7 & \text { Yes No }\end{array}$

$\begin{array}{llllllll}1 & 2 & 3 & 4 & 5 & 6 & 7 & \text { Yes No }\end{array}$

$\begin{array}{llllllll}1 & 2 & 3 & 4 & 5 & 6 & 7 & \text { Yes No }\end{array}$

$\begin{array}{llllllll}1 & 2 & 3 & 4 & 5 & 6 & 7 & \text { Yes No }\end{array}$

$\begin{array}{llllllll}1 & 2 & 3 & 4 & 5 & 6 & 7 & \text { Yes No }\end{array}$

$\begin{array}{llllllll}1 & 2 & 3 & 4 & 5 & 6 & 7 & \text { Yes No }\end{array}$

$\begin{array}{llllllll}1 & 2 & 3 & 4 & 5 & 6 & 7 & \text { Yes No }\end{array}$ 
APPENDIX C

Parent Attitude Scale

Never Seldom Sometimes Often Always

1. I enjoy my child.

$\begin{array}{lllllll}1 & 2 & 3 & 4 & 5 & 6 & 7\end{array}$

2. I feel like I am a good parent.

$\begin{array}{lllllll}1 & 2 & 3 & 4 & 5 & 6 & 7\end{array}$

3. I get along well with my child.

$\begin{array}{lllllll}1 & 2 & 3 & 4 & 5 & 6 & 7\end{array}$

4. I am glad I have children. $\begin{array}{llllllll}1 & 2 & 3 & 4 & 5 & 6 & 7\end{array}$

5. I feel my child appreciates me.

$\begin{array}{lllllll}1 & 2 & 3 & 4 & 5 & 6 & 7\end{array}$

6. I understand my child.

$\begin{array}{lllllll}1 & 2 & 3 & 4 & 5 & 6 & 7\end{array}$


APPENDIX D

Outline of Group Sessions

$\underline{\text { Session } 1}$

I. Administer tests

A. Eyberg Children's Behavior Inventory

B. Parent Attitude Scale

II. Introduction

A. Discuss the purpose of sessions

1. Parenting is sometimes a difficult job requiring a variety of skills. In the next few weeks, we will address some of the problems you are faced with in day-to-day child rearing and learn new techniques to help with the behavior management of children.

III. Discussion

A. Have the parents share with the group what their life was like before they had children.

1. What kind of expectations did they have from marriage, having a family?

B. Encourage group members to share with each other what their life is like now.

1. Are some of those earlier expectations met?

2. In what ways do they now feel disappointed? How have expectations not been met?

C. Have them share the good things in their lives now. Explore those things that make them feel good with regard to their children.

IV. Lecture

A. Values

1. There is no one way of child rearing. The techniques that we will be working with will provide ways in which to change behaviors. It will be up to each group member to decide what behaviors to work on.

B. Whose problem is it?

1. Examples of ways in which parents shape their child's behavior.

(a) A small child shows a drawing he has done to his father. His father says, "That's a 
lovely picture, son. I really like it." The chance that the child will show things to his father is increased.

(b) A child imitates a dancer on TV. The parents laugh and clap. The likelihood that the child will do it again increases.

2. Example of way in which child shapes the parents' behavior.

(a) A mother has told her child that she can't have any candy before dinner. The child throws a tantrum. The mother, tired of the screaming, lets her child have the candy.

V. Discussion

A. Who changes? Is it the parent or the child?

\section{$\underline{\text { Session } 2}$}

I. Lecture

A. Behavior in situations: Discussion based on the principle that most behavior is learned.

1. Behaviors don't occur alone. There is an event that follows the behavior. These events, or consequences, that follow the behavior affect whether or not the behavior is repeated.

2. We will mainly be looking at behaviors that are affected by their consequences. There will be behaviors we want to increase, some we want to decrease, and some behaviors we want to eliminate.

B. Observing behavior

1. The behavior in question needs to be looked at in combination with the situation in which it occurs. Keeping a record of the behavior to be changed may be a helpful way to begin.

(a) Examples of record-keeping methods.

2. Begin to notice what happens before the behavior you have been observing occurs and after it occurs.

(a) Examples of antecedent-behavior-consequence.

(1) Mother is on the telephone, child begins to whine and interrupt the mother, mother hangs up. 
(2) Child trips, falls down, and cries for mother. Mother comforts child.

C. Reinforcements

1. It is the consequence that needs to be changed to alter the behavior.

2. A reinforcement is an event that follows a behavior and increases the likelihood that the behavior will occur again. Examples: Refer to the two examples above. Talk about alternative consequences and the ways in which they might affect the behavior.

3. Recall that in the first session their children's good behaviors were discussed.

(a) Good behaviors sometimes go ignored. For example: A child is playing nicely with a sibling so the parent ignores the child. Instead, the parent could say, "I like the way you are playing with your brother." This increases the chance of the child playing nicely with his brother.

(b) Desirable behaviors must be attended to to be increased. This attention must be given immediately and consistently following the desirable behavior.

(c) If we only react to negative behaviors it may be these behaviors that increase.

II. Group discussion

A. Discuss the things members enjoy about their children and how they can be increased.

\section{Session 3}

I. Review

A. Reinforcement--repeat definition. Give examples of positive reinforcers (praise, hugs, smiles, candy, etc.)

1. Stress praise. Praise is a powerful reinforcer that is easily available. Lots of specific labeled praise is valuable. Tell your child exactly what it is that you like or that pleases you. This increases the likelihood that the behavior will continue and helps build the child's self-confidence. Rather than punishing your child for bad behavior, give your child lots of positive reinforcement and praise for good behaviors. Soon the good behavior will increase and the bad behavior will decrease. 
B. The importance of immediacy

C. The importance of consistency

D. Good behaviors sometimes go ignored

II. Group discussion

A. Discuss any concerns group has in using positive reinforcement.

B. Have group members share positive behaviors they have observed in their children during the week.

1. What methods (if any) have they used to reinforce these behaviors.

C. Have each group member select a specific behavior that they would like to see increased in their child. Have the group give ideas of various reinforcers that can be used to increase the behavior.

$\underline{\text { Session } 4}$

I. Re-issue ECBI

II. Review discussion held the previous week on positive reinforcement.

III. What can we do with these behaviors that we want to modify or eliminate?

A. Punishment

1. Behavior that is punished will occur less often.

Two types of punishment.

(a) After a behavior is performed, something unpleasant occurs. Example: Child says a naughty word and is scolded by his parents.

(b) After a child behaves in a particular way, something pleasant is removed. Example:

A child is playing with her parents, she says

a naughty word and is removed to another room by herself.

2. Sometimes punishment doesn't work. The undesirable behavior may be resistant to the punishment.

3. Punishment alone doesn't teach new behaviors.

B. Extinction--A child has learned a behavior because it was reinforced. If the behavior is no longer reinforced, it will weaken and, as time goes by, disappears altogether. To extinguish a behavior, ignore it. 
1. The difference between punishment and extinction: In punishment an unpleasant event occurs following a behavior. In extinction, nothing happens. Example: A child is being loud and rude. The parent sends the child from the room (or spanks her, etc.). This is punishment. If extinction is used, the parent does not condem or punish the child in any way for loudness or rudeness. In other words, the behavior brings no noticeable response. The parent does respond to behavior that is cooperative and friendly by verbal approval, attention, perhaps joining her play. The child learns that she can get attention for desirable behavior.

2. This treatment may sound contrary to "common sense." Parents don't often realize that they may perpetuate antisocial behavior by labeling it, punishing, showing their disapproval, thus making it evident that the child could upset or annoy them.

c. It is important not to use criticism or ask yes and no questions. It is also important to give clear, simple commands. Example: It is time to go to bed now (not "okay?"). You can offer a choice: Do you want to take your doll or teddy bear?

1. Give the child a chance to respond.

2. If the directions are followed, immediately reinforce with praise, hug.

3. If child ignores the command, be sure child understands the command.

4. Use physical re-direction or gestures.

5. Punishment.

D. If a child displays behavior that you feel is inappropriate, first decide if the behavior can be ignored. Ask yourself if it is attention-getting and nondestructive. If you can't ignore it, a time-out is one approach that may be effective. Example: Bobby is hitting his sister. Give a clear command: "Bobby, stop hitting your sister." Bobby hits sister again. "You didn't stop hitting your sister so now you will have to stay in the bathroom until I tell you to come out. Calmly take Bobby to bathroom. If Bobby is quiet for three minutes, tell him he can come out. If he yells or cries, wait until he has been quiet for a few minutes before letting him come out. If he repeats the inappropriate behavior, calmly repeat the process. Be certain to praise the next good behavior. 
IV. Group discussion

A. Discuss the behaviors that they selected last week for reinforcement.

B. Have parents talk about some behaviors they would like to decrease or extinguish.

c. Have group explore various ways of doing this.

Session 5

I. Review the major principles

A. Positive reinforcement

1. Reward

2. Immediacy

3. Consistency

B. Extinction

1. Ignore inappropriate, attention-seeking behavior

C. Punishment

1. Loss of privileges

2. Time-outs

II. Discussion

A. Ask each group member to describe a behavior they would like to work on. Emphasize increasing positive behaviors when possible.

B. Have the group give ideas on ways to increase/decrease the various behaviors that are discussed.

C. Have group members role play as many of these as possible.

$\underline{\text { Session } 6}$

I. Review techniques, emphasizing reinforcers.

A. Ask group for examples of positive reinforcers they have used during the week.

B. Group discussion of specific problems, possible solutions.

C. Role play problems, solutions.

II. Administer tests

A. ECBI

B. Parent Attitude Scale 